\title{
A Novel Tetranuclear Silver Compound with bis(3,5-dimethylpyrazol-1-yl)acetate: a Simple Synthesis Yielding Complex Crystal Structure
}

\author{
Marta Počkaj and Nives Kitanovski* \\ Faculty of Chemistry and Chemical Technology, University of Ljubljana, Večna pot 113, SI-1000 Ljubljana, Slovenia. \\ *Corresponding author: E-mail: nives.kitanovski@fkkt.uni-lj.si.
}

Received: 05-21-2021

\begin{abstract}
A novel tetranuclear silver coordination compound with the formula $\left[\mathrm{Ag}_{4}\left(\mathrm{bdmpza}_{4}\right] \cdot 10 \mathrm{H}_{2} \mathrm{O}(\mathrm{bdmpza}=\mathrm{bis}(3,5\right.$-dimethylpyrazol-1-yl)acetate) was synthesized by a reaction between an aqueous solution of silver nitrate and an aqueous solution prepared by bis(3,5-dimethylpyrazol-1-yl)acetic acid and potassium hydroxide (1:1 molar ratio). The obtained compound was characterized by elemental analysis, coupled thermogravimetric-mass spectrometry analysis, vibrational IR spectroscopy, and its crystal structure was determined by single-crystal X-ray diffraction method. Furthermore, the obtained crystal structure was additionally evaluated by Hirshfeld surface analysis.
\end{abstract}

Keywords: coordination chemistry; silver; bis(3,5-dimethylpyrazol-1-yl)acetate; crystal structure; Hirshfeld surface analysis.

\section{Introduction}

Due to the modelling of active sites of some zinc enzymes, and of active sites of the non-heme iron enzymes, which are required in oxygen activation, diverse tripodal heteroscorpionate $N, N, \mathrm{O}$ ligands have been prepared in last decades. Such type of compounds can serve as suitable structural mimics for the facial 2-His-1-carboxylate triad, since they express high binding affinity to occupy a trigonal face of coordination polyhedron. ${ }^{1-4}$ Numerous compounds based on bis(pyrazol-1-yl)acetate with pyrazolyl rings substituted at 3 and 5 positions are reported. ${ }^{5}$

The scarcity of suitable $N, N, \mathrm{O}$-triple ligands initially led to model compounds with $N, N, N$-binding sites. First $\mathrm{N}, \mathrm{N}, \mathrm{N}$-tris(pyrazolyl)borate-complexes were reported by Trofimenko in the late 1970s. ${ }^{6}$ In 1999, the first two compounds, lithium and niobium, with bis(3,5-dimethylpyrazol-1-yl)acetate (bdmpza) were published. ${ }^{7}$ Crystal structure of bis(pyrazol-1-yl)acetic acid (Hbpza) and its synthetic route, as well the synthesis of bis(3,5-dimethylpyrazol-1-yl)acetic acid (Hbdmpza), were reported two years later. ${ }^{5,8}$ So far, variety of mono, di-, tetra- and hexanuclear metal complexes with bis(3,5-dimethylpyrazol-1-yl) acetate have been reported. ${ }^{4,7,9-13}$ Among all the described compounds, formed by the routes with bis(3,5-dimeth- ylpyrazol-1-yl)acetic acid, only two complexes are known in which the acetate group is not deprotonated, $[\mathrm{Cu}(\mathrm{Hbd}-$ mpza $\left.)_{2}\right]\left(\mathrm{HSO}_{4}\right)_{2}$ and $\left[\mathrm{Cu}(\mathrm{Hbdmpza})_{2}\right] \mathrm{Cl}_{2}$. Two $\mathrm{Cu}(\mathrm{II})$ compounds with methyl ester acetate group were previously published as well. ${ }^{14,15}$

On the other hand, silver is known to be bioactive and this property is widely exploited in different everyday products as well as in medical devices, especially when in form of nano- or colloidal silver or different binary silver compounds. For this reason the research on the coordination chemistry of silver(I) has increased dramatically in last decades, and it became widely known that silver complexes with oxygen and nitrogen atoms exhibit different antimicrobial activities among others. ${ }^{16,17}$ Furthermore, the silver(I) complexes have found different applications in material science for their structural diversity originating from a $d^{10}$ electron configuration which allows the formation of different coordination geometries and represent a foundation for construction of supramolecular frameworks. ${ }^{18,19,20}$

Herein we report the crystal structure of first silver coordination compound with bdmpza ligands. The compound was also characterized by Hirshfeld surface analysis, coupled thermogravimetric-mass spectrometry analysis and infrared spectroscopy. 


\section{Experimental}

\section{1. Materials and Physical Measurements}

All reagents and chemicals were purchased from commercial sources and used without further purification. Bis(3,5-dimethylpyrazol-1-yl)acetic acid was synthesized as reported previously. ${ }^{5}$ An aqueous solution of bis(3,5-dimethylpyrazol-1-yl)acetate was prepared by bis(3,5-dimethylpyrazol-1-yl)acetic acid and sodium hydroxide in 1:1 molar ratio.

CHN elemental analyses were performed with a PerkinElmer 2400 CHN Elemental Analyzer. The infrared spectra were measured on solid samples using a Perkin-Elmer Spectrum 100 series FT-IR spectrometer equipped with an ATR sampling accessory.

Coupled thermogravimetric-mass spectrometry analysis (TG-MS) measurements were performed on a Mettler Toledo TGA/DSC1 instrument under dynamic flow of argon. Around $1.2 \mathrm{mg}$ of the sample was put into $150 \mu \mathrm{L}$ platinum crucible and heated from $25^{\circ} \mathrm{C}$ to $700{ }^{\circ} \mathrm{C}$ with a heating rate of $10 \mathrm{~K} \mathrm{~min}^{-1}$. Evolved gases were introduced into Balzers ThermoStar mass spectrometer via $75 \mathrm{~cm}$ long heated capillary. To lower the water content in the mass spectrometer, the sample was kept at $25^{\circ} \mathrm{C}$ for $15 \mathrm{~min}$ at the beginning of the mesurement. Blank curve was subtracted.

\section{2. Synthesis}

To the aqueous solution of silver nitrate, $\mathrm{AgNO}_{3}$, (0.10 mmol, i.e. $1.0 \mathrm{~mL}$ of $0.10 \mathrm{M}$ solution) $1.0 \mathrm{~mL}$ of the aqueous solution prepared of bis(3,5-dimethylpyrazol-1-yl)acetic acid $(0.040 \mathrm{mmol})$ and potassium hydroxide $(0.040 \mathrm{mmol})$ was added. The obtained precipitate was filtered off and colourless solution was left in a closed beaker, wrapped in aluminium foil, in the dark space, to prevent reduction of $\mathrm{Ag}(\mathrm{I})$ to elemental silver. The colourless prismatic crystals which are also light-sensitive appeared in 17 days. Yield: $3.68 \mathrm{mg}$ (23\%). Anal. Calcd. for $\mathrm{C}_{48} \mathrm{H}_{80} \mathrm{Ag}_{4} \mathrm{~N}_{16} \mathrm{O}_{18}$ : C, 36.02\%; H, $5.04 \%$;, $14.00 \%$. Found: C, 35.87\%; H, $5.19 \%$; N, 14.21\%. $v_{\max }: 3180(\mathrm{vw}$ $v(\mathrm{OH}), 1651\left(\mathrm{vs}, v_{\mathrm{as}}(\mathrm{OCO})\right), 1614\left(\mathrm{vs}, v_{\mathrm{as}}(\mathrm{OCO})\right), 1556(\mathrm{~s}$, $v(\mathrm{CN}), 1463(\mathrm{~m}, v(\mathrm{CN}), 1443(\mathrm{~m}), 1417$ (s, $v(\mathrm{CC})), 1384$ (m), $1345\left(\mathrm{vs}, v_{\mathrm{s}}(\mathrm{OCO})\right), 1327(\mathrm{vs}), 1299(\mathrm{~m}), 1255(\mathrm{v}$, $\left.v_{\mathrm{s}}(\mathrm{OCO})\right), 1146(\mathrm{w}), 1113(\mathrm{w}), 1034(\mathrm{~s}), 896(\mathrm{w}), 875(\mathrm{~s})$, $801(\mathrm{~s}), 768(\mathrm{ws}), 711(\mathrm{~s}), 650(\mathrm{w}), 626(\mathrm{w}), 618(\mathrm{w})$.

\subsection{X-Ray Crystallography}

For X-ray structural analysis, single crystal of the title compound was surrounded by silicon grease, mounted onto the tip of glass fibre and transferred to the goniometer head in the liquid nitrogen cryostream. Data were collected on a SuperNova diffractometer equipped with Atlas detector using CrysAlis software and monochromated Mo Ka radiation $(0.71073 \AA)$ at $150 \mathrm{~K} .{ }^{21}$ The initial structural model was obtained via direct methods using the SIR97 structure solution program. ${ }^{22}$ A full-matrix least-squares refinement on $F^{2}$ magnitudes with anisotropic displacement parameters for all nonhydrogen atoms using SHELXL-2018/3 was employed. ${ }^{23}$ All $\mathrm{H}$ atoms were initially located in difference Fourier maps; those residing on $\mathrm{C}$-atoms were further treated as riding on their parent atoms with $\mathrm{C}$ (aromatic) $-\mathrm{H}$ distance and $\mathrm{C}$ (methyl)- $\mathrm{H}$ distances of 0.95 and $0.98 \AA$, respectively. On the other hand, the hydrogen atoms bonded to oxygen atoms were refined in the beginning and due to unstable refinement, they were treated using AFIX 3 command at the very last refinement cycles. Details on crystal data, data collection and structure refinement are given in Table 1. Figures depicting the structures were prepared with Mercury. ${ }^{24}$

Table 1. Crystal data, data collection and refinement.

\begin{tabular}{|c|c|}
\hline \multicolumn{2}{|l|}{ Crystal data } \\
\hline Formula & $\mathrm{C}_{48} \mathrm{H}_{80} \mathrm{Ag}_{4} \mathrm{~N}_{16} \mathrm{O}_{18}$ \\
\hline$M_{\mathrm{r}}$ & 1600.76 \\
\hline Cell setting, space group & Triclinic, $P-1$ \\
\hline$a(\AA)$ & $10.8581(4)$ \\
\hline$b(\AA)$ & $12.6003(6)$ \\
\hline$c(\AA)$ & $12.9796(5)$ \\
\hline$\alpha\left(^{\circ}\right)$ & $72.307(4)$ \\
\hline$\beta\left(^{\circ}\right)$ & $89.235(3)$ \\
\hline$\gamma\left({ }^{\circ}\right)$ & $71.190(4)$ \\
\hline$V\left(\AA^{3}\right)$ & $1594.39(12)$ \\
\hline$Z$ & 1 \\
\hline$D_{\mathrm{x}}\left(\mathrm{Mg} \mathrm{m}^{-3}\right)$ & 1.667 \\
\hline$\mu\left(\mathrm{mm}^{-1}\right)$ & 1.288 \\
\hline$F(000)$ & 812 \\
\hline Crystal form, colour & Prism, colourless \\
\hline Crystal size $\left(\mathrm{mm}^{3}\right)$ & $0.4 \times 0.3 \times 0.3$ \\
\hline \multicolumn{2}{|l|}{ Data collection } \\
\hline$T(\mathrm{~K})$ & $150(2)$ \\
\hline $\begin{array}{l}\text { No. of measured, independent } \\
\text { and observed reflections }\end{array}$ & $14694,8314,6539$ \\
\hline$R_{\text {int }}$ & 0.0293 \\
\hline \multicolumn{2}{|l|}{ Refinement } \\
\hline$R\left(\right.$ on $\left.F_{\text {obs }}\right), w R$ (on $\left.F_{\text {obs }}\right), S$ & $0.0340,0.0646,1.060$ \\
\hline No. of contributing reflections & 8314 \\
\hline No. of parameters & 406 \\
\hline No. of restraints & 0 \\
\hline$\Delta \rho_{\max }, \Delta \rho_{\min }\left(\mathrm{e} \AA^{-3}\right)$ & $0.754,-0.906$ \\
\hline
\end{tabular}

\section{3. Hirshfeld Surface Analysis}

To study intermolecular interactions in the title compound, the Hirshfeld surface analyses were performed using Crystal Explorer, both based on the results of previous single crystal X-ray diffraction study. ${ }^{25,26}$ The Hirshfeld surfaces were plotted over three quantities: a) $d_{\text {norm }}$, 
plotted in red-white-blue colour code, representing shorter/close to the sum of van der Waals radii/longer contacts between the molecules, b) curvedness and c) shape index, in which red areas represent hollows and blue areas represents bumps. Additionally, the full and resolved 2D fingerprint plots that show distances from each point on the Hirshfeld surface to the nearest atom inside $\left(d_{\mathrm{i}}\right)$ and outside $\left(d_{\mathrm{e}}\right)$ of it were calculated.

\section{Results and Discussion}

\section{1. Crystal Structure}

The tetranuclear molecule, $\left[\mathrm{Ag}_{4}(\text { bdmpza })_{4}\right]$ (Fig. 1), is surrounded by ten solvent water molecules. The asymmetric unit consists of half of the coordination moiety and five water molecules, while the other half is formed by an inversion centre. Two of symmetry independent bdmpza ligands are coordinated in different manners. The first bdmpza ligand acts as a tetradentate ligand and thus fulfils its binding potential coordinating via its both nitrogen atoms and both oxygen atoms from deprotonated carboxylate group. Such tetradentate coordination of bdmpza ligand is observed very rarely, only in four crystal structures where the bdmpza is coordinated to two different metal centres. ${ }^{27,28}$ Contrary to the first bdmpza ligand, the second bdmpza ligand is bound tridentately via both of its $\mathrm{N}$-atoms and additional $\mathrm{O}$ from deprotonated carboxylate group; such tridentate coordination of bdmpza is prevalent, it appears in more than $90 \%$ of crystal structures with bdmpza in a role of ligand. ${ }^{9}$

As a consequence of the described coordination modes of bdmpza ligands, both symmetry independent silver ions are coordinated differently (the relevant bonds and

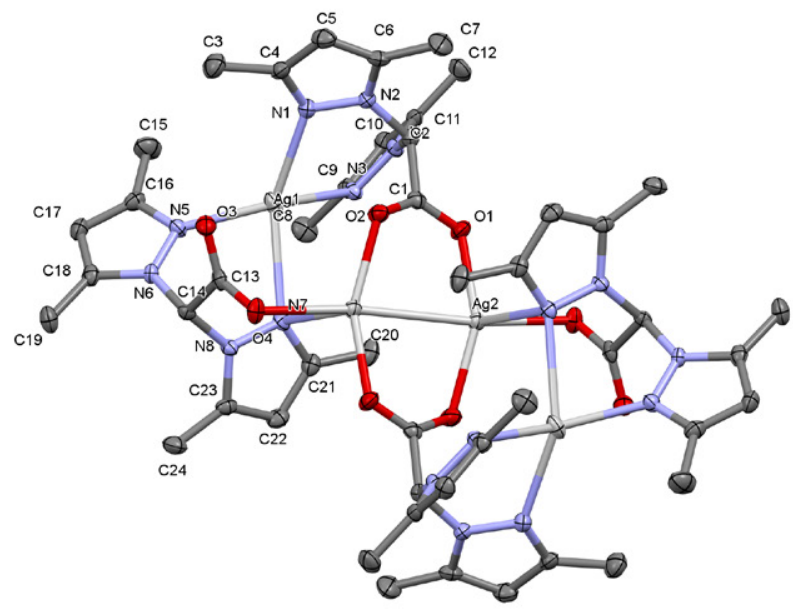

Figure 1. ORTEP representation of tetranuclear coordination molecules $\left[\mathrm{Ag}_{4}(\mathrm{bdmpza})_{4}\right]$. Only the atoms in the asymmetric unit are labeled. The thermal ellipsoids are given at $30 \%$ probability level while hydrogens and water molecules are omitted for clarity. The strong argentophilic interaction between Ag2 and its symmetry equivalent is also shown. angles around the metal centres are given in Table 2). Ag1 is coordinated with four nitrogens, a pair from each of the two bdmpza ligands, possessing a seesaw geometry as indicated $\tau_{4}$ value of $0.523 .{ }^{29}$ In other words, the geometry around $\mathrm{Ag} 1$ is somewhere between the ideal tetrahedral and square planar geometries (the value of 0.497 for $\tau_{4}{ }^{c}$ does not completely confirm the intermediate seesaw geometry).$^{30}$ It is worth mentioning that the fourth nitrogen atom (N7) is further away than the previous three (N1, N3, N5) and thus close to the upper limit of such contacts. Therefore, such coordination environment of Ag1 might also be described as trigonal with additional contact (i.e. $3+1$ ) but usually, despite of the significant difference in bondlegths, such coordination number is still considered to be four. The longest bond can be regarded as secondary and still important coordination interaction. Such situation often occurs when multidentate ligands with limited flexibility are present. ${ }^{31-33}$

On the other hand, Ag2 is coordinated with three oxygen atoms each from one of three different bdmpza ligands and one nitrogen atom further away. The relevant $\tau_{4}$ and $\tau_{4}$ 'values are 0.683 indicating severely distorted tetrahedral geometry around Ag2. The coordination sphere of Ag2 is accomplished by Ag2' obtained by inversion centre which is positioned in between them. Additionally, Ag2 and Ag2' are bridged by two carboxylate bridges, bringing both atoms to the distance of 2.9062(4) $\AA$ which represents very strong argentophilic interaction. ${ }^{34,35}$

Although the tetrasilver compounds are frequent in coordination chemistry of silver(I), such tetrasilver cluster $\mathrm{Ag}_{4} \mathrm{O}_{6} \mathrm{~N}_{8}$ as found in the title compound has not been observed yet. ${ }^{9}$ The same holds true for the presence of tetradentately and tridentately coordinated bdmpza ligand: to the best of our knowledge, the title compound is the first that contains bdmpza ligands ligated in both manners to the metal centre.

Table 2. Selected bond lengths and angles $\left(\AA{ }^{\circ}\right)$ for the title compound.

\begin{tabular}{|c|c|c|c|}
\hline Ag1-N1 & $2.368(2)$ & N1-Ag1-N3 & $80.55(8)$ \\
\hline Ag1-N3 & $2.311(2)$ & N1-Ag1-N5 & $122.41(8)$ \\
\hline Ag1-N5 & $2.199(2)$ & N1-Ag1-N7 & $147.30(7)$ \\
\hline Ag1-N7 & $2.622(2)$ & N3-Ag1-N5 & $139.02(8)$ \\
\hline $\mathrm{Ag} 2-\mathrm{O} 1^{i}$ & $2.229(2)$ & N3-Ag1-N7 & $97.54(7)$ \\
\hline $\mathrm{Ag} 2-\mathrm{O} 2^{i}$ & $2.245(2)$ & N5-Ag1-N7 & $80.02(7)$ \\
\hline $\mathrm{Ag} 2-\mathrm{O} 4^{i}$ & $2.380(2)$ & $\mathrm{O} 1-\mathrm{Ag} 2-\mathrm{O} 2^{i}$ & $154.34(8)$ \\
\hline $\mathrm{Ag} 2-\mathrm{N} 7^{i}$ & $2.582(2)$ & $\mathrm{O} 1-\mathrm{Ag} 2-\mathrm{O} 4^{i}$ & $88.75(7)$ \\
\hline \multirow[t]{8}{*}{$\mathrm{Ag} 2-\mathrm{Ag} 2^{i}$} & $2.9062(4)$ & $\mathrm{O} 1-\mathrm{Ag} 2-\mathrm{N} 7^{i}$ & $106.73(7)$ \\
\hline & & $\mathrm{O} 2^{i}-\mathrm{Ag} 2-\mathrm{O} 4^{i}$ & $109.32(7)$ \\
\hline & & $\mathrm{O} 2^{i}-\mathrm{Ag} 2-\mathrm{N} 7^{i}$ & $95.48(7)$ \\
\hline & & $\mathrm{O} 4^{i}-\mathrm{Ag} 2-\mathrm{N} 7^{i}$ & $76.27(7)$ \\
\hline & & $\mathrm{O} 1-\mathrm{Ag} 2-\mathrm{Ag} 2^{i}$ & $82.51(5)$ \\
\hline & & $\mathrm{O} 2^{i}-\mathrm{Ag} 2-\mathrm{Ag} 2^{i}$ & $77.89(5)$ \\
\hline & & $\mathrm{O} 4^{i}-\mathrm{Ag} 2-\mathrm{Ag} 2^{i}$ & $170.51(4)$ \\
\hline & & $\mathrm{N} 7^{i}-\mathrm{Ag} 2-\mathrm{Ag} 2^{i}$ & $109.75(5)$ \\
\hline
\end{tabular}

Symmetry codes: $(i)-x+1,-y,-z+1$. 
Molecular entities in the title crystal structure are intensely connected with hydrogen bonds (Table 3, Figs. 2 and 3). The $\mathrm{O}-\mathrm{H} \cdots \mathrm{O}$ hydrogen bonds strongly dominate and connect either coordination clusters with water molecules or water molecules with adjacent water molecules. As shown in Fig. 2, the $\mathrm{O}-\mathrm{H} \cdots \mathrm{O}$ interactions lead to the formation of characteristic five-membered ring defined by oxygen atoms which are further connected and as a consequence, parallel zig-zag chains of interchanging water and coordination molecules are formed as shown in Fig. 3. These are further connected by $\mathrm{C}-\mathrm{H} \cdots \mathrm{O}$ interactions. Note that in Table 3 only the hydrogen bonds compliant with classical criteria, i.e. $\mathrm{D}-\mathrm{H} \cdots \mathrm{A}$ angle $>110^{\circ}, \mathrm{O} \cdots \mathrm{O}$ distance $<3.04 \AA$ and $\mathrm{C}$... O distance $<3.22 \AA$ are given. Additional C- $\mathrm{H}^{\cdots} \mathrm{O}$ interactions are present between the zig-zag chains, for which the $\mathrm{C} \cdots \mathrm{O}$ distances are significantly larger than the sum of van der Waals radii. Such bonds are

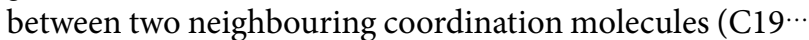
$\mathrm{O} 4{ }^{i}, 3.402(3) \AA$ ) and between coordination and water mo-

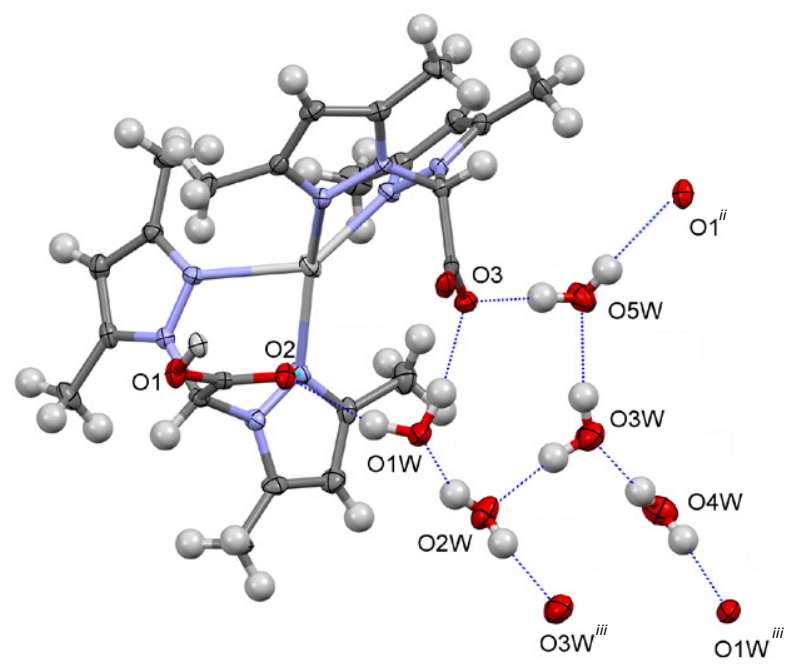

Figure 2. A branched hydrogen bond network around the asymmetric unit; for clarity, only $\mathrm{H}$-bonds in an asymmetric unit are shown.

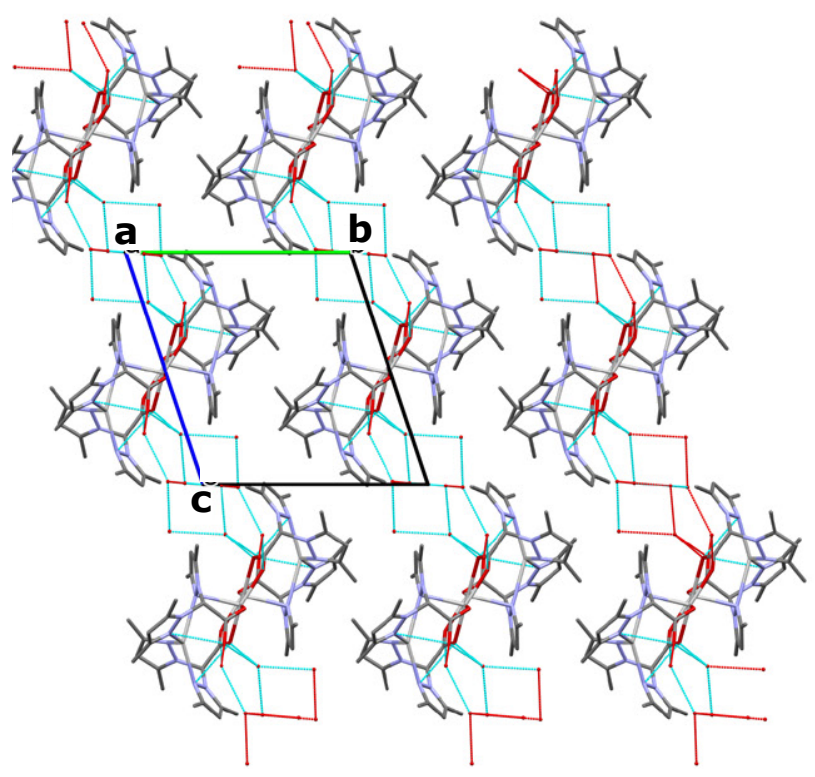

Figure 3. A view down $a$ axis on crystal packing. $\mathrm{O}-\mathrm{H} \cdots \mathrm{O}$ hydrogen bonds between water-water or water-coordination molecule lead to the formation of parallel zig-zag chains. Hydrogen atoms and $\mathrm{C}-\mathrm{H} \cdots \mathrm{O}$ interactions are omitted for clarity.

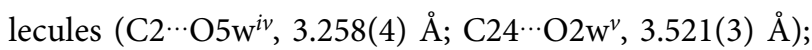
the corresponding symmetry codes are as given under Table 3.

\section{2. Hirshfeld Surface Analysis}

To additionally evaluate the intermolecular interactions in the crystal structure, Hirshfeld surface (HS) analysis was used. Fig. 4a represents Hirshfeld surface of tetranuclear coordination molecule mapped over $d_{\text {norm }}$ in a range from $-0,6379$ to +1.6617 arbitrary units. The intense red spots in the vicinity of oxygens and hydrogens indicate donors and acceptors of $\mathrm{O}-\mathrm{H} \cdots \mathrm{O}$ interactions, i.e. hydrogen bonds between coordination molecule and adjacent water molecules. HS mapped over curvedness and shape index (Figs. $4 \mathrm{~b}$ and $4 \mathrm{c}$ ) indicate the absence of broad

Table 3. Hydrogen bond geometry in $\mathrm{C}_{48} \mathrm{H}_{80} \mathrm{Ag}_{4} \mathrm{~N}_{16} \mathrm{O}_{18}$.

\begin{tabular}{|c|c|c|c|c|c|}
\hline $\mathrm{D}-\mathrm{H} \cdots \mathrm{A}$ & D-H $(\AA)$ & H...A (Å) & D...A $(\AA)$ & D-H...A $\left({ }^{\circ}\right)$ & Symmetry code of $A$ \\
\hline $\mathrm{C} 14-\mathrm{H} 14 \cdots \mathrm{O} 4$ & 1.00 & 2.30 & $3.129(3)$ & 139.7 & $i$ \\
\hline $\mathrm{O} 1 \mathrm{~W}-\mathrm{H} 1 \mathrm{WA} \cdots \mathrm{O} 2$ & 0.92 & 2.06 & $2.903(3)$ & 152.3 & - \\
\hline $\mathrm{O} 1 \mathrm{~W}-\mathrm{H} 1 \mathrm{WB} \cdots \mathrm{O} 3$ & 0.91 & 1.97 & $2.834(3)$ & 156.6 & - \\
\hline $\mathrm{O} 5 \mathrm{~W}-\mathrm{H} 5 \mathrm{WB} \cdots \mathrm{O} 1$ & 0.86 & 2.13 & $2.953(3)$ & 160.2 & $i i$ \\
\hline O5W-H5WA $\cdots \mathrm{O} 3$ & 0.86 & 1.91 & $2.750(3)$ & 166.6 & - \\
\hline $\mathrm{O} 2 \mathrm{~W}-\mathrm{H} 2 \mathrm{WB} \cdots \mathrm{O} 1 \mathrm{~W}$ & 0.89 & 1.98 & $2.822(3)$ & 158.3 & - \\
\hline $\mathrm{O} 2 \mathrm{~W}-\mathrm{H} 2 \mathrm{WA} \cdots \mathrm{O} 3 \mathrm{~W}$ & 0.89 & 1.98 & $2.857(3)$ & 168.9 & $i i i$ \\
\hline $\mathrm{O} 3 \mathrm{~W}-\mathrm{H} 3 \mathrm{WA} \cdots \mathrm{O} 2 \mathrm{~W}$ & 0.84 & 1.97 & $2.784(4)$ & 161.1 & - \\
\hline $\mathrm{O} 3 \mathrm{~W}-\mathrm{H} 3 \mathrm{WB} \cdots \mathrm{O} 5 \mathrm{~W}$ & 0.86 & 2.02 & $2.872(3)$ & 167.4 & - \\
\hline $\mathrm{O} 4 \mathrm{~W}-\mathrm{H} 4 \mathrm{WA} \cdots \mathrm{O} 3 \mathrm{~W}$ & 0.87 & 2.08 & $2.949(3)$ & 173.2 & - \\
\hline $\mathrm{O} 4 \mathrm{~W}-\mathrm{H} 4 \mathrm{WB} \cdots \mathrm{O} 1 \mathrm{~W}$ & 0.84 & 2.14 & $2.971(3)$ & 170.0 & - \\
\hline
\end{tabular}

iii Symmetry codes: (i) $-x+2,-y,-z+1$; (ii) $x+1, y, z$; (iii) $-x+2,-y,-z$; (iv) $x-1, y, z$; (v) $x, y, z+1$. Note that symmetry codes

(iv) and $(v)$ refer to the information in text. 

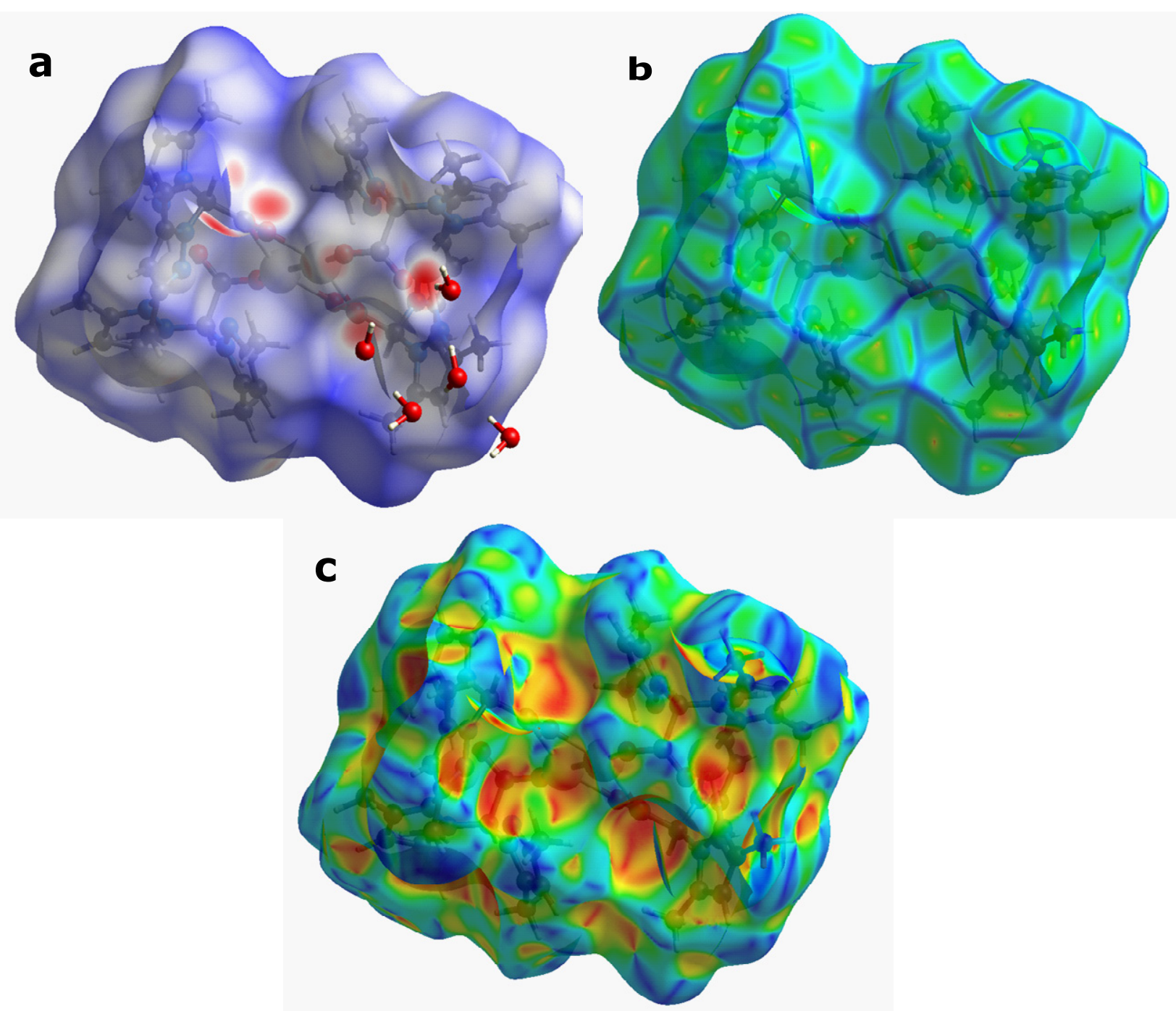

Figure 4. Hirshfeld surface of coordination molecule $\left[\mathrm{Ag}_{4}(\mathrm{bdmpza})_{4}\right]$; a) plotted over $d_{\text {norm }}$ in the range from $-0,6379$ to $+1,6617$ a. u., together with the adjacent water molecules, b) plotted over curvedness (range from -4.000 to 0.4000 ), and c) plotted over shape-index (range from -1.000 to $1.000)$.

flat regions that disable planar stacking of the coordination molecules, and also show the bumps and hollows to represent the touching of the molecules.

Additionally, selected 2D fingerprint plots for the coordination molecules are shown in Fig. 5, i.e. for all contacts as well as for individual $\mathrm{H} \cdots \mathrm{H}, \mathrm{O} \cdots \mathrm{H} / \mathrm{H} \cdots \mathrm{O}, \mathrm{C} \cdots \mathrm{H}$ / $\mathrm{H} \cdots \mathrm{C}$ and $\mathrm{N} \cdots \mathrm{H} / \mathrm{H} \cdots \mathrm{N}$ contacts, whose percentage to the total Hirshfeld surface area is also given. These contacts comprise more than $99 \%$ of the HS area; the other two minor contributions are from $\mathrm{C} \cdots \mathrm{O} / \mathrm{O} \cdots \mathrm{C}$ and $\mathrm{Ag} \cdots \mathrm{H}$ / $\mathrm{H} \cdots \mathrm{Ag}$ contacts. The $\mathrm{H} \cdots \mathrm{H}$ interactions are in the middle of the scattered points in the $2 \mathrm{D}$ fingerprint plots with an overall contribution of $60.8 \%$ (Fig. $5 \mathrm{~b}$ ). Two sharp spikes at $d_{\mathrm{i}}+d_{\mathrm{e}}$ at $\sim 1.8$ and $2.1 \AA$, respectively, represent the reciprocal $\mathrm{O} \cdots \mathrm{H} / \mathrm{H} \cdots \mathrm{O}$ interactions (Fig. 5c) contributing $18.4 \%$ to the total HS. C...H/H...C and N...H/H...N interactions appear as broad shoulders at $d_{\mathrm{i}}+d_{\mathrm{e}}$ around 2.6 $\AA ̊$ (Figs. 5d and 5e).

\section{3. Coupled Thermogravimetric-Mass Spectrometry Analysis}

The TG curve of the title compound in argon flow shows two-step thermal degradation and a total mass loss of $68.58 \%$. The mass loss starts at room temperature and ends at about $400{ }^{\circ} \mathrm{C}$ and proceeds in two distinctive steps as observed in Fig. 6 . The first step starts already at the beginnig of isothermal measurement at $25^{\circ} \mathrm{C}$ and ends at around $80{ }^{\circ} \mathrm{C}$ with $10.49 \%$ mass loss. The observed mass loss correpsonds to the dehydration (calc. 11.25\%). At the end of this step small signal $\mathrm{m} / \mathrm{z}=18$ was detected in mass spectrometer, confirming dehydration. Since at the beginnig of the measureument there is high water content in the system, signals due to water evolution are relatively low. The second mass loss step of 58.09\% from 150-400 ${ }^{\circ} \mathrm{C}$ represents the thermal decomposition of four bdmpza ligands; during this step evolution of $\mathrm{CO}_{2}(\mathrm{~m} / \mathrm{z}=44)$ and 


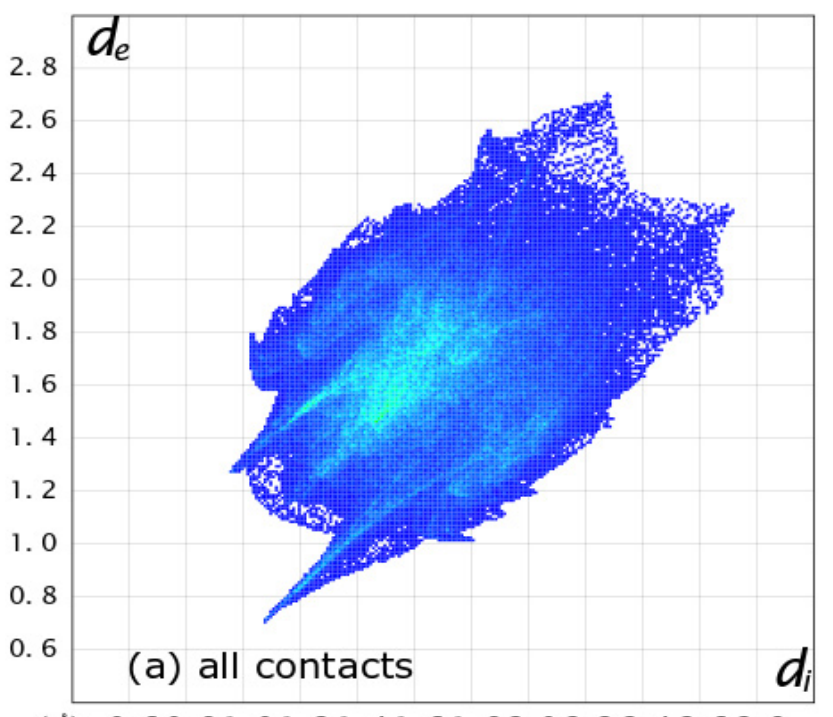

(A) 0.60 .81 .01 .21 .41 .61 .82 .02 .22 .42 .62 .8

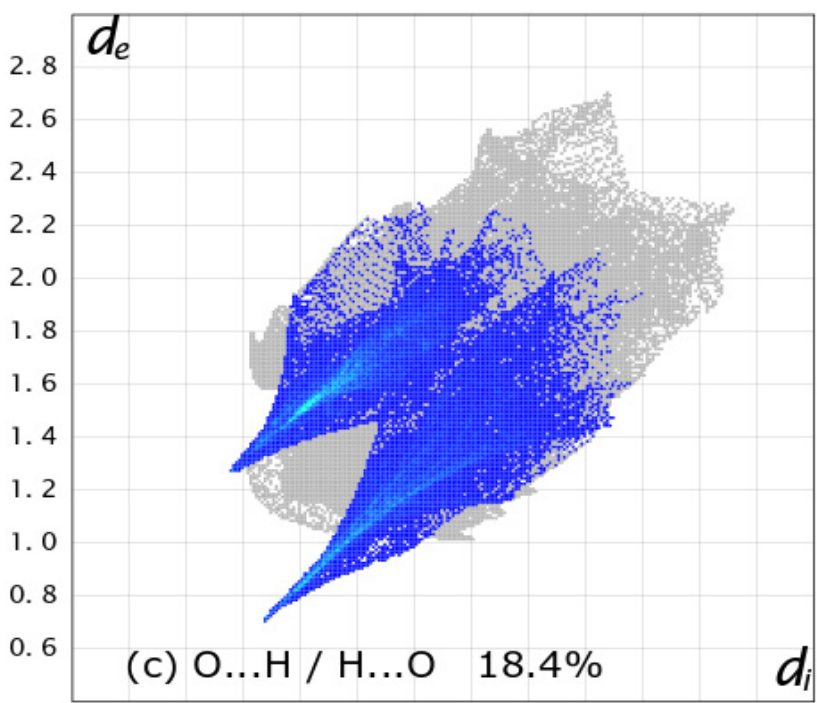

(A) 0.60 .81 .01 .21 .41 .61 .82 .02 .22 .42 .62 .8

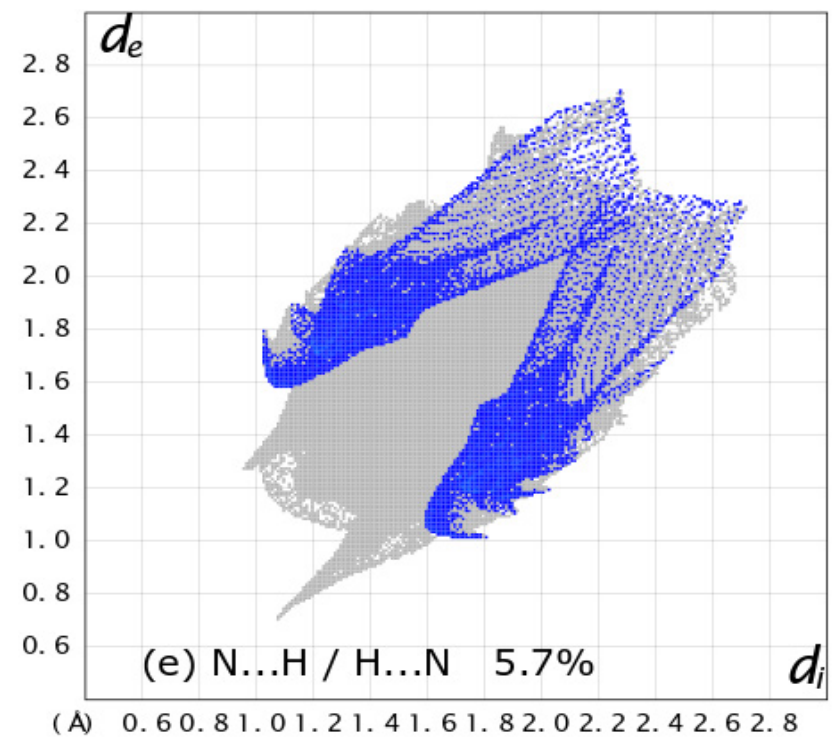

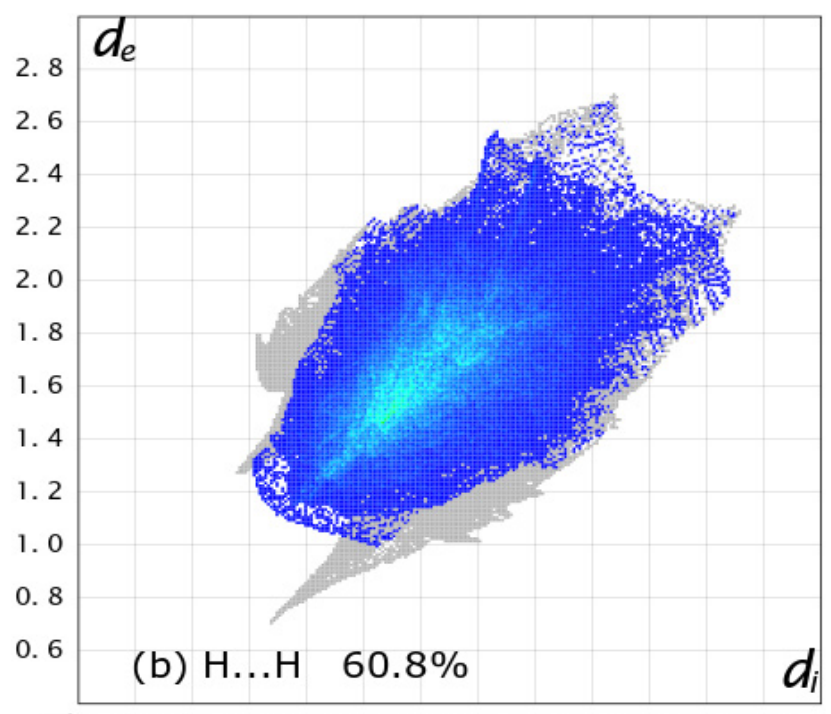

(A) 0.60 .81 .01 .21 .41 .61 .82 .02 .22 .42 .62 .8

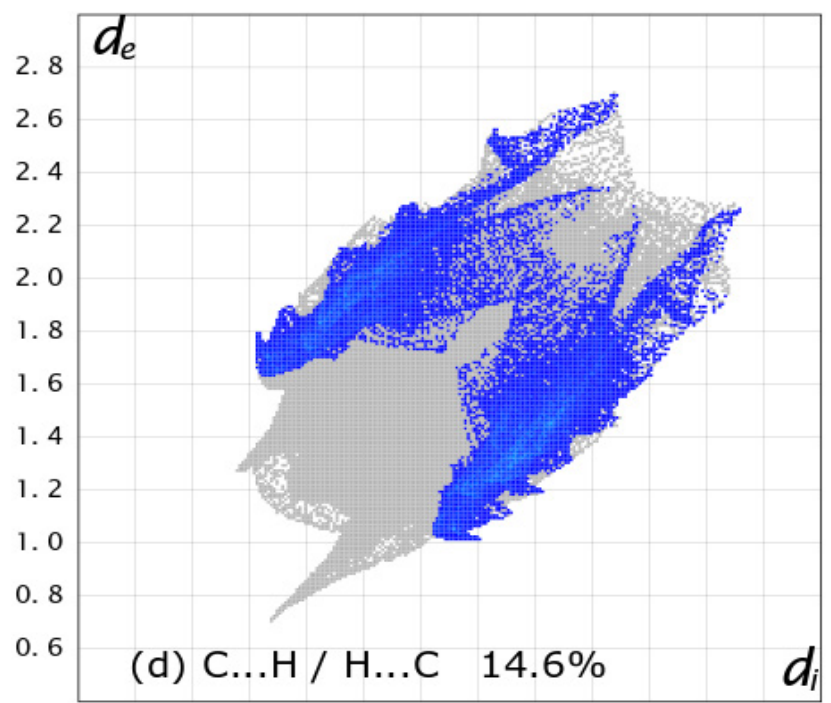

(A) 0.60 .81 .01 .21 .41 .61 .82 .02 .22 .42 .62 .8

\footnotetext{
Figure 5. a) A full 2D fingerprint plot of $\left[\mathrm{Ag}_{4}(\mathrm{bdmpza})_{4}\right]$ coordination molecule, together with those resolved into b) $\mathrm{H} \cdots \mathrm{H}, \mathrm{c}$ ) $\mathrm{O} \cdots \mathrm{H} /$ $\mathrm{H} \cdots \mathrm{O}$, d) $\mathrm{C} \cdots \mathrm{H} / \mathrm{H} \cdots \mathrm{C}$ and e) $\mathrm{N} \cdots \mathrm{H} / \mathrm{H} \cdots \mathrm{N}$ contacts.
} 


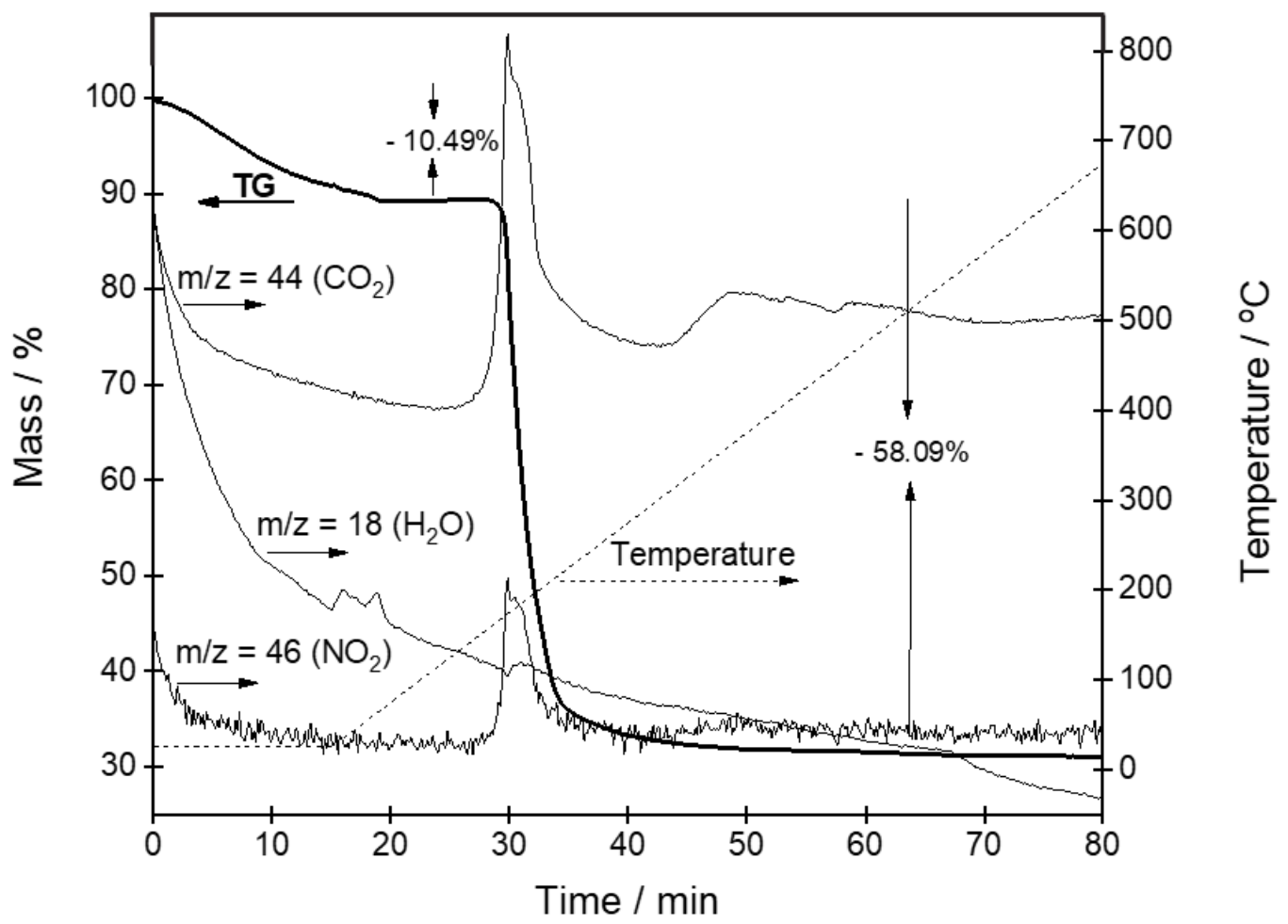

Figure 6. Coupled TG-MS curves of the title compound.

$\mathrm{NO}_{2}(\mathrm{~m} / \mathrm{z}=46)$ was detected. For complete removal of bdmpza during this step the theoretical mass loss would be $61.79 \%$ of the initial mass. However, as different oxidizing products are formed during this step, the residue after the thermal treatment is $\mathrm{Ag}_{2} \mathrm{O}$. The mass of solid residue represents $31.42 \%$ of the starting mass which is in accordance with the theoretically expected (28.96\%).

\section{4. Infrared Spectroscopy}

In the infrared spectrum (Fig. 7) bands belonging to the vibrations of water molecules and bdmpza ligand can be assigned. The weak broad band at approx. 3200 $\mathrm{cm}^{-1}$ can be attributed to the $\mathrm{O}-\mathrm{H}$ stretching in water molecules. The broadness of the band confirms the intense participation of such bonds in the hydrogen bond

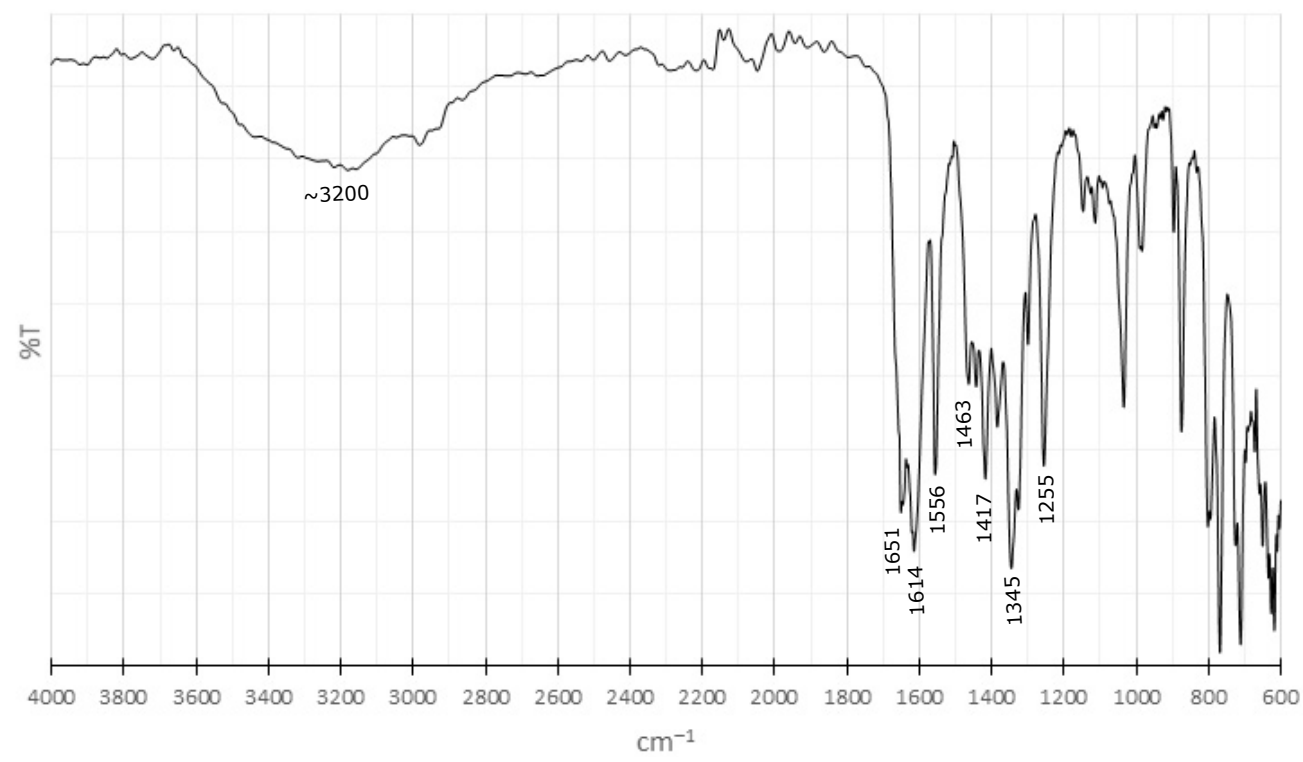

Figure 7. Vibrational IR spectrum of the title compound. 
network. Since carboxylate groups of bdmpza ligand are coordinated to metal centers in two different modes, two pairs of bands belonging to the (OOC) stretching vibrations can be observed: (a) asymmetric longitudinal valence oscillations of carboxylate groups appear as two strong bands at 1651 and $1614 \mathrm{~cm}^{-1}$, while (b) symmetric OOC stretching is also observed in a shape of two separated strong bands at 1345 and $1255 \mathrm{~cm}^{-1}$, respectively. Bands at 1556 and $1463 \mathrm{~cm}^{-1}$ can be attributed to the stretches of the $\mathrm{C}=\mathrm{N}$ and $\mathrm{C}-\mathrm{N}$ bonds of pyrazole rings. $\mathrm{A}$ band that appears in the spectra at $1417 \mathrm{~cm}^{-1}$ is probably the band of longitudinal oscillation of the $\mathrm{C}-\mathrm{C}$ bonds in rings. ${ }^{4,36}$

\section{Conclusions}

A new coordination compound $\left[\mathrm{Ag}_{4}(\mathrm{bdm}\right.$ pza $\left.)_{4}\right] \cdot 10 \mathrm{H}_{2} \mathrm{O}$ (bdmpza = bis(pyrazol-1-yl)acetate) was prepared by the reaction between an aqueous solution of silver nitrate and an aqueous solution of bis(3,5-dimethylpyrazol-1-yl)acetic acid and potassium hydroxide (1:1 molar ratio). The structure represents the first silver(I) coordination compound with bdmpza ligands in which the first bdmpza is tetra- and the second bdmpza is tridentately coordinated. The tetrasilver cluster $\mathrm{Ag}_{4} \mathrm{O}_{6} \mathrm{~N}_{8}$ forms which has not been observed till now. The coordination molecule $\left[\mathrm{Ag}_{4}(\mathrm{bdmpza})_{4}\right]$ is surrounded by ten water molecules and an extense hydrogen bond network is formed. The TG-MS curve of the title compound in argon flow shows two-step of thermal degradation with a total mass loss of $68.58 \%$, attributed to the dehydration (11.25\%) and the thermal decomposition of four bdmpza ligands (58.09\%). In the infrared spectrum, the vibrations of water molecules and bdmpza ligand can be assigned. The broadness of the weak $\mathrm{O}-\mathrm{H}$ stretching band indicates the presence of intense hydrogen bond network in the compound. Unidentate and bidentate bonding of carboxylate groups of ligands reflects in two pairs of bands belonging to the (OOC) stretching vibrations, asymmetric and symmetric.

\section{Supplementary Information}

CCDC 2053074 contains the supplementary crystallographic data. These data can be obtained free of charge from The Cambridge Crystallographic Data Centre via www.ccdc.cam.ac.uk/data_request/cif.

\section{Acknowledgments}

This work was financially supported by Slovenian research agency (grant P1-0175). The authors thank Matej Jarc Rydzi for the synthesis of the ligand and EN-FIST Centre of Excellence for the use of SuperNova diffractometer.

\section{References}

1. S. Trofimenko, Scorpionates, The Coordination Chemistry of Polypyrazolylborate Ligands, Imperial College Press, London, 2005.

2. C. Pettinari, R. Pettinari, Coord. Chem. Rev. 2005, 249, 663691. DOI:10.1016/j.ccr.2004.08.017

3. N. Burzlaff, Adv. Inorg. Chem. 2008, 60, 101-165. DOI:10.1016/S0898-8838(08)00004-4

4. A. Beck, A. Barth, E. Hubner, N. Burzlaff, Inorg. Chem. 2003, 42, 7182-7188. DOI:10.1021/ic034097c

5. A. Beck, B. Weibert, N. Burzlaff, Eur. J. Inorg. Chem. 2001, 521-527 DOI:10.1002/1099-0682(200102)2001:2<521::AID -EJIC521>3.0.CO;2-Q

6. S. Trofimenko, J. Am. Chem. Soc. 1967, 89, 3170. DOI:10.1021/ja00989a016

7. A. Otero, J. Fernandez-Baeza, J. Tejeda, A. Antinolo, F. Carrillo-Hermosilla, E. Diez Barra, A. Lara-Sanchez, M. Fernandez-Lopez, M. Lanfranchi, M. A Pellinghelli, J. Chem. Soc., Dalton Trans. 1999, 3537-3539. DOI:10.1039/a907505d

8. N. Burzlaff, I. Hegelmann, B. Weibert, J. Organomet. Chem. 2001, 626, 16-23. DOI:10.1016/S0022-328X(01)00648-9

9. C. R. Groom, I. J. Bruno, M. P. Lightfoot, S. C. Ward, Acta Crystallogr. 2016, B72, 171-179.

DOI:10.1107/S2052520616003954

10. C. Pettinari, R. Pettinari, Coord. Chem. Rev. 2005, 249, 663691. DOI:10.1016/j.ccr.2004.08.017

11. A. Otero, J. Fernandez-Baeza, A. Antinolo, J. Tejeda, A. Lara-Sanchez, L. Sanchez-Barba, M. Fernandez-Lopez, I. Lopez-Solera, Inorg. Chem. 2004, 43, 1350-1358.

DOI:10.1021/ic035067c

12. B. Weibert, N. Burzlaff, Eur. J. Inorg. Chem. 2003, 339-347. DOI:10.1002/ejic.200390046

13. A. Pevec, B. Kozlevčar, P. Gamez, J. Reedijk, Acta Crystallogr. 2007, E63, m514-m516. DOI:10.1107/S1600536807001493

14. B. Kozlevčar, P. Gamez, Z. Jagličić, P. Strauch, N. Kitanovski, J. Reedijk, Eur. J. Inorg. Chem. 2011, 3650-3655.

DOI:10.1002/ejic.201100410

15. B. Kozlevčar, T, Pregelj, A. Pevec, N. Kitanovski, J, S, Costa, G, van Albada, P, Gamez, J. Reedijk, Eur. J. Inorg. Chem. 2008, 31, 4977-4982. DOI:10.1002/ejic.200800557

16. B. S. Fox, M. K. Beyer, V. E. Bondybey, J. Am. Chem. Soc. 2002, 124, 13613-13623. DOI:10.1021/ja0176604

17. N. D. Savić, B. Glišić, H. Wadepohl, A. Pavić, S. Lidija, J. Nikodinović-Runić, M. I. Djuran, Med. Chem. Commun. 2016, 7, 282-291. DOI:10.1039/C5MD00494B

18. C.-F. Liu, Z.-G. Ren, J.-P. Lang, Eur. J. Inorg. Chem. 2019 1816-1824. DOI:10.1002/ejic.201900026

19. F. R. Knight, R. R. M. Randall, L. Wakefield, A. M. Z. Slawin, J. D. Woollins, Dalton Trans. 2013, 42, 143-154. DOI:10.1039/C2DT31390A

20. L. Zhao, L.-Y. Xie, X.-L. Du, K. Zheng, T. Xie, R.-R. Huang, J. Qin, J.-P. Ma, L.-H. Ding, Acta Chim. Slov. 2020, 67, 822-829. DOI:10.17344/acsi.2019.5784

21. CrysAlisPRO, Oxford Diffraction /Agilent Technologies UK Ltd, Yarnton, England. 
22. A. Altomare, M. C. Burla, M. Camalli, G. L. Cascarano, C. Giacovazzo, A. Guagliardi, A. G. G. Moliterni, G. Polidori, R. Spagna, J. Appl. Cryst. 1999, 32, 115-119.

DOI:10.1107/S0021889898007717

23. G. M. Sheldrick, Acta Crystallogr. 2015, C71, 3-8.

24. C. F. Macrae, P. R. Edgington, P. McCabe, E. Pidcock, G. P. Shields, R. Taylor, M. Towler, J. van de Streek, J. Appl. Crystallogr. 2006, 39, 453-457. DOI:10.1107/S002188980600731X

25. M. J. Turner, J. J. McKinnon, S. K. Wolff, D. J. Grimwood, P. R. Spackman, D. Jayatilaka, M. A. Spackman, CrystalExplorer17. University of Western Australia, 2017.

26. M. A. Spackman, D. Jayatilaka, Cryst. Eng. Comm. 2009, 11, 19-32. DOI:10.1039/B818330A

27. J. L. Rhinehart, K. A. Manbeck, S. K. Buzak, G. M. Lippa, W. W. Brennessel, K. I. Goldberg, W. D. Jones, Organometallics 2012, 31, 1943-1952. DOI:10.1021/om2012419

28. A. Beyer, M. S. von Gernler, S. Pflock, G. Turkoglu, L. Muller, A. Zahl, K. Gieb, P. Muller, T. Drewello, N. Burzlaff, Eur. J. Inorg. Chem. 2018, 765-777. DOI:10.1002/ejic.201701400
29. A. Okuniewski, D. Rosiak, J. Chojnacki, B. Becker, Polyhedron 2015, 90, 47-57. DOI:10.1016/j.poly.2015.01.035

30. D. Rosiak, A. Okuniewski, J. Chojnacki, Polyhedron 2018, 146, 35-41. DOI:10.1016/j.poly.2018.02.016

31. M. Szymanska, M. Insinska-Rak, G. Dutkiewicz, G. N. Roviello, M. A. Fik-Jaskolka, V. Patroniak, J. Mol. Liq. 2020, 319, 114182 DOI:10.1016/j.molliq.2020.114182

32. M. H. H. Wurzenberger, V. Braun, M. Lommel, T. M. Klapotke, J. Stierstorfer, Inorg. Chem. 2020, 59, 10938

DOI:10.1021/acs.inorgchem.0c01403

33. S. Racioppi, M. Andrzejewski, V. Colombo, A. Sironi, P. Macchi, Inorg. Chem. 2020, 59, 2223

DOI:10.1021/acs.inorgchem.9b02852

34. H. Schmidbaur, A. Schier, Angew. Chem. Int. Ed. 2014, 53, 2-41. DOI:10.1002/anie.201490000

35. M. Drev, U. Grošelj, D. Kočar, F. Perdih, J. Svete, B. Štefane, F. Požgan, Inorg. Chem. 2020, 59, 3993-4001.

DOI:10.1021/acs.inorgchem.9b03664

36. G. B. Deacon, R. J. Philips, Coord. Chem. Rev. 1980, 33, $227-$ 250. DOI:10.1016/S0010-8545(00)80455-5

\section{Povzetek}

Pripravili smo novo štirijedrno spojino srebra s formulo $\left[\mathrm{Ag}_{4}(\mathrm{bdmpza})_{4}\right] \cdot 10 \mathrm{H}_{2} \mathrm{O}$ (bdmpza = bis(3,5-dimetilpirazol-1-il) acetat). Spojino smo sintetizirali z reakcijo med vodno raztopino, pripravljeno iz bis(3,5-dimetilpirazol-1-il)ocetne kisline in kalijevega hidroksida v množinskem razmerju 1:1 ter vodno raztopino srebrovega nitrata. Dobljen produkt smo analizirali z elementno analizo, termogravimetrično analizo sklopljeno z masno spektrometrijsko analizo, vibracijsko IR spektroskopijo, njeno kristalno strukturo pa smo določili z metodo rentgenske difrakcije na monokristalu. Kristalna struktura je bila dodatno ovrednotena $\mathrm{z}$ analizo Hirshfeldovih površin. 